\title{
Análise das superfícies de saída e de folga de ferramentas de corte empregadas no torneamento de ferro fundido cinzento perlítico com diferentes adições de nióbio
}

\author{
Bárbara C. Mendanha Reis ${ }^{1,2 *}$, Anderson Júnior dos Santos ${ }^{1,3}$, Natália F. Santos Pereira ${ }^{1}$, \\ Denílson José do Carmo ${ }^{4,5}$, Marcelo Araújo Câmara ${ }^{1}$, Paulo Eustáquio de Faria 1 \\ 1 Universidade Federal de Minas Gerais, CEP: 31270-901, Belo Horizonte MG, , Brasil. \\ ${ }^{2}$ Universidade Federal de Ouro Preto, Campus Universitário do Morro do Cruzeiro, Ouro Preto, \\ CEP: 35400-000, Brasil. \\ ${ }^{3}$ Instituto Federal Sudeste de Minas Gerais Campus Muriaé, Muriaé, CEP 36884-036, MG, Brasil. \\ ${ }^{4}$ Centro Tecnológico de Fundição Marcelino Corradi-SENAI-CETEF-Itaúna CEP 35680-270, MG, \\ Brasil. \\ ${ }^{5}$ Universidade de Itaúna, Itaúna CEP 35680-142, MG, Brasil \\ *e-mail: barbara.reis@ufop.edu.br,
}

\begin{abstract}
Cast iron corresponds to the second most used metallic material worldwide. However, its production has shown reductions, mainly due to the development of lighter materials. In this sense, metallurgical efforts have been made to add elements to obtain different solid solutions that would lead to the improvement and guarantee of the diversity of this alloy. However, modifications of any kind to the properties of a material have an impact on its machinability. Thus, this work aimed to evaluate the influence of the addition of niobium $(0.21-0.24 \%$ by weight) in a pearlitic gray cast iron alloy (equivalent to the EN-GJL-250 class) on the wear of the tools of cemented carbide (class K20) during the turning. The wear on the rake and clearance surfaces was qualitatively evaluated via scanning electron microscopy (SEM) and X-ray dispersive energy spectroscopy (EDS). Together, the chemical composition variation occurred with the chip breaker geometry: tools with chip breaker (GH) or without chip breaker (Flat Top). All these variations were indifferent in relation to the wear of the tools and their mechanisms. Regardless of the chemical composition, material of the machined part was found adhered to both the rake surface and the clearance of all cutting tools. In addition, grooves were found in the flank, suggesting the abrasion mechanism.
\end{abstract}

Keywords: Gray cast iron; niobium; tool wear; ME V; EDS. 
Resumo. O ferro fundido corresponde ao segundo material metálico mais utilizado mundialmente. Entretanto, sua produção tem apresentado reduções, principalmente, devido ao desenvolvimento de materiais mais leves. Nesse sentido, esforços metalúrgicos têm sido conduzidos para a adição de elementos a fim de obter diferentes soluções sólidas que levariam à melhoria e garantia da diversidade desta liga. No entanto, modificações de qualquer natureza nas propriedades de um material causam impacto em sua usinabilidade. Dessa maneira, este trabalho teve como objetivo avaliar a influência da adição de nióbio (0,21-0,24\% em peso) em uma liga de ferro fundido cinzento perlítico (equivalente à classe EN-GJL-250) no desgaste das ferramentas de corte de metal duro classe K20 durante a operação de torneamento. O desgaste das superfícies de saída e de folga foram avaliados de maneira qualitativa via microscopia eletrônica de varredura (MEV) e espectroscopia de energia dispersiva de Raio-X (EDS). Conjuntamente a variação da composição química ocorreu a variação da geometria do quebra-cavaco: ferramentas com quebra-cavaco (GH) ou sem quebra-cavaco (Flat Top). Todas estas variações foram indiferentes em relação ao desgaste das ferramentas e seus mecanismos. Independentemente da composição química, material da peça usinada foi encontrado aderido tanto na superfície de saída quanto na de folga de todas as ferramentas de corte. Além disso, foram encontradas ranhuras no flanco, sugerindo o mecanismo de abrasão.

Palavras-chaves: Ferro fundido cinzento; nióbio; desgaste da ferramenta; MEV; EDS.

\section{Introduction}

$\mathrm{O}$ ferro fundido cinzento se distingue de outras ligas devido à suas excelentes propriedades autolubrificantes durante processos de usinagem. Tal fato se deve às grafitas lamelares que ao serem cortadas formam uma camada de lubrificante sólido, e consequentemente, favorecem menor desgaste e vida mais longa para as ferramentas de corte (KLOCKE, 2011). Stephenson e Agapiou (2016) verificaram que a vida da ferramenta de corte diminuiu a medida que a dureza do ferro fundido cinzento aumentou. Klocke (2011) adicionou fatores microestruturais como quantidade, tamanho, forma e distribuição da grafita, porcentagem de ferrita e perlita e a presença de inclusões e carbonetos à vida da ferramenta de corte.

Trent e Wright (2000) ressaltaram que o comportamento do ferro fundido cinzento no plano de cisalhamento durante o corte pode ser previsto a partir de sua resistência mecânica e falta de ductilidade, porém, na interface entre ferramenta e peça de trabalho, na zona de cisalhamento secundário, este comportamento seria menos convencional. A Figura 
1 descreve o processo de formação do cavaco e destaca o aspecto da grafita lamelar da peça de ferro fundido cinzento. Pode-se esperar que a grafita lamelar atue inibindo o seizure (uma forte adesão) na interface cavaco ferramenta, mas não há evidências comprovadas (TRENT e WRIGHT, 2000).

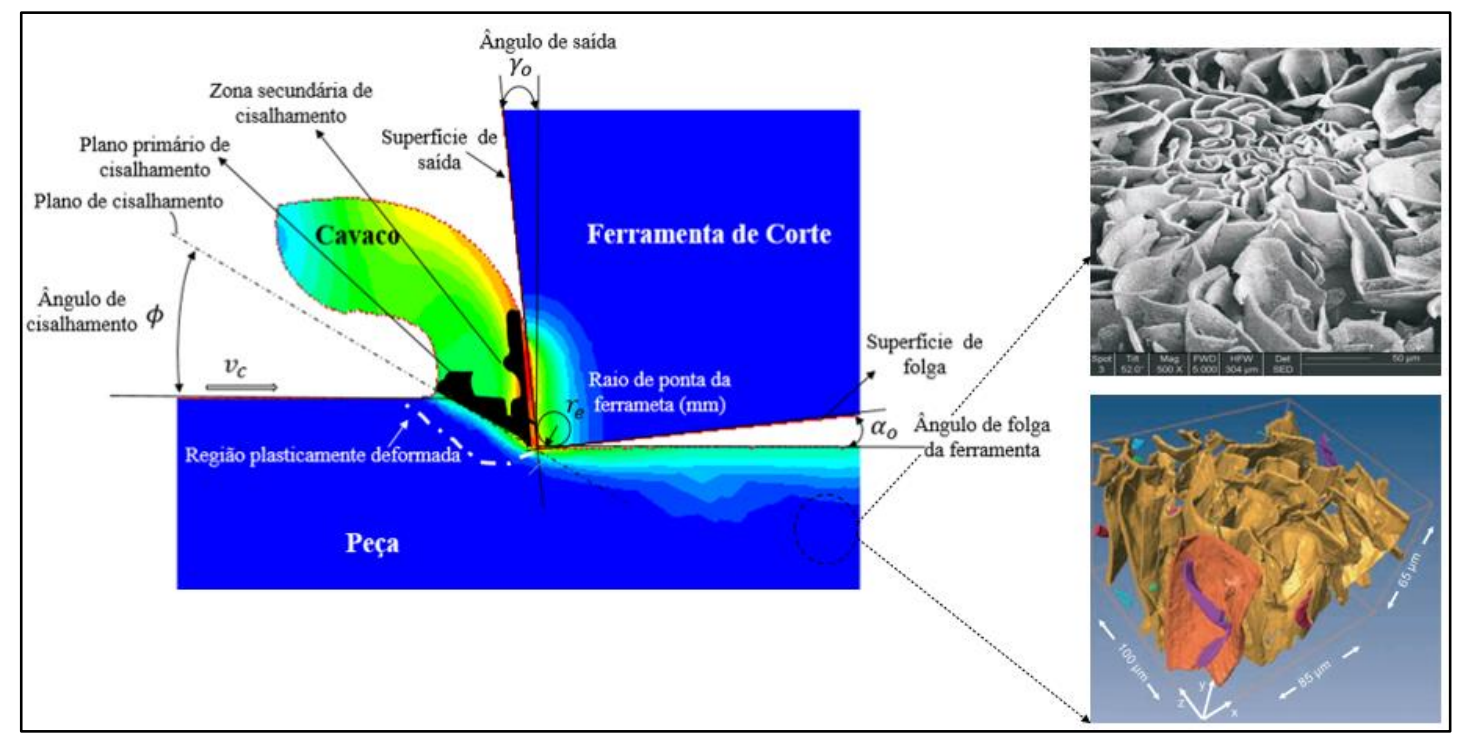

Figura 1- O processo de formação de cavaco e a grafita lamelar no ferro fundido cinzento. Fonte: adaptado de Velichko, Holzapfel e Muecklich (2007)

Klocke (2011) ilustrou as principais formas de desgaste que ocorrem em ferramentas de corte durante o torneamento, conforme descrito na Figura 2. Na superfície de saída, observa-se desgaste de cratera e, na superfície de folga, o desgaste de flanco (Figura 2). Dependendo dos parâmetros de corte (velocidade de corte (vc), avanço (f) e profundidade de usinagem (ap)) e da combinação dos materiais da peça e da ferramenta de corte, o desgaste de flanco tende a ser mais intenso na aresta de corte, continuando na superfície de folga. Já o desgaste de entalhe é causado pelas transições bruscas de tensões mecânica e térmica, prevalecendo na extremidade da área de contato. Por fim, a ocorrência de avaria (trinca, lascamento ou quebra) é rara em operações de corte contínuo, como o torneamento, pois, nesse tipo de processo, a ocorrência de choques mecânicos e térmicos é baixa. 


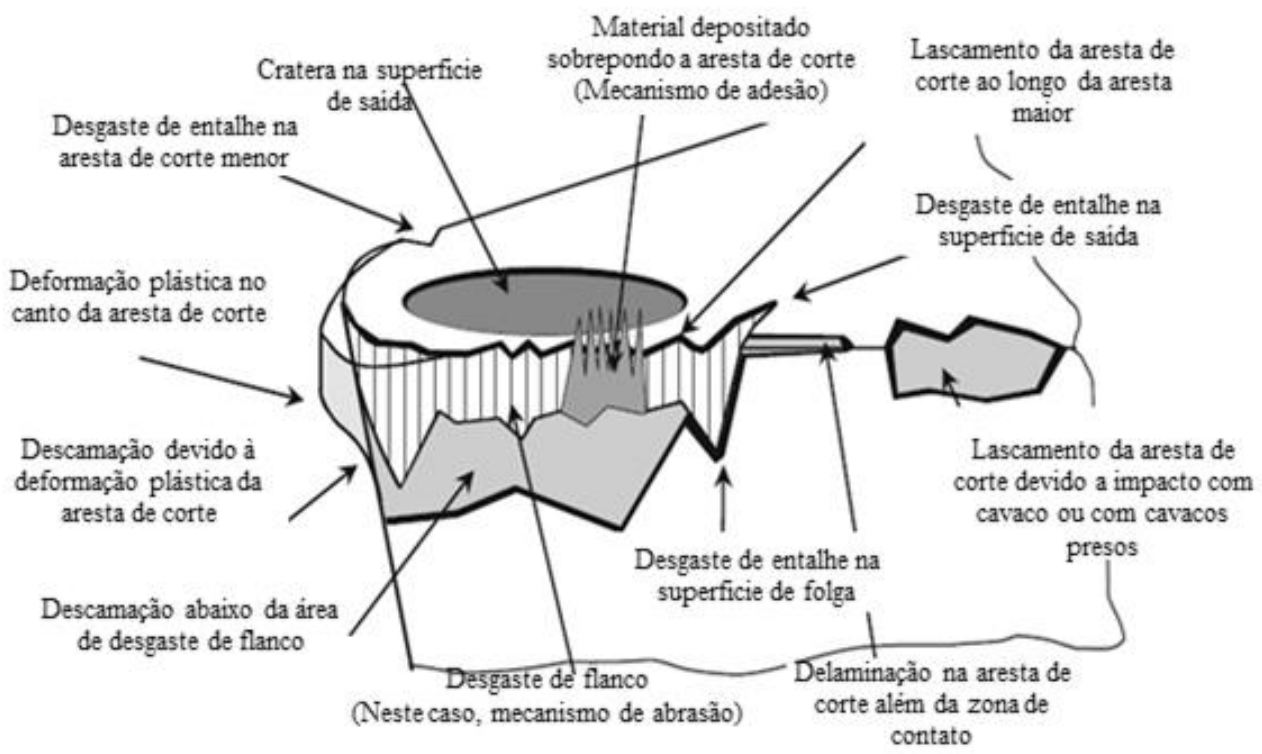

Figura 2 - Formas características de desgaste na ferramenta de corte durante o processo de torneamento. Fonte: adaptado de Klocke (2011)

Pereira (2005) detalhou que durante o processo de usinagem uma película protetora poderia ser formada sobre as superfícies da ferramenta de corte devido às inclusões de engenharia. Tal película é conhecida como camada protetora (BUL, do inglês built-up layer), e no caso do ferro fundido cinzento, o sulfeto de manganês em condições favoráveis de temperatura, pressão, energia de superfície e afinidade química formaria esta camada protetora sobre as superfícies da ferramenta de corte. Nesse sentido, Trent e Wright (2000) explicaram que o ferro fundido cinzento não tende a fazer com que uma cratera se forme na superfície de saída da ferramenta e, consequentemente, é comum o emprego de ferramentas de metal duro durante o corte deste material. A BUL foi associada por Trent e Wright (2000) como a razão para a ausência de formação de crateras e por Grzesik (2017) como a razão da usinagem mais fácil do ferro fundido cinzento em relação aos ferros fundidos nodular e vermicular.

A BUL reduz a força de corte por meio do aumento do ângulo de cisalhamento bem como diminui o coeficiente de atrito na interface cavaco ferramenta (PEREIRA, 2005). Ademais, reduz o calor gerado na região primária do cisalhamento, e consequentemente, atua como uma barreira de difusão e proteção contra o desgaste. Heck et al. (2008) verificaram diferença no tempo de vida da ferramenta no torneamento de ferro fundido cinzento e vermicular e a explicaram a partir da formação da camada de MnS. 
Klocke (2011) explicou que a camada protetora se estabelece apenas em velocidades de corte de acima de 200 m.min-1, tornando-se cada vez mais espessa com o aumento da temperatura do corte. No entanto, Tooptong, Park e Kwon (2018) verificaram que a camada de MnS não foi observada em ferramentas de corte de metal duro não revestidas até mesmo para vc de 600 m.min-1. Portanto, estes autores afirmaram que sua existência deveria ser atribuída com cautela ao explicar a excelente usinabilidade do ferro fundido cinzento. Fiorini e Byrne (2016) esclareceram que é frequentemente relatado que uma BUL se forma mais prontamente em vc mais altas (750-2500 m.min-1) dado uma composição adequada da peça de trabalho e da temperatura da zona de corte. Logo, é necessária uma temperatura suficientemente alta para reduzir a viscosidade da inclusão, facilitando a transferência e a deposição da BUL sobre a superfície de saída da ferramenta.

Em relação os mecanismos de desgaste, Machado et al. (2015) ordenaram abrasão, adesão e difusão como os principais tipos de desgaste na usinagem do ferro fundido cinzento. Liu et al. (2017) verificaram as superfícies de flanco desgastadas de ferramentas de corte de nitreto de silício (Si3N4) não revestidas e revestidas com nitreto de cromo alumínio (CrAlN) e nitreto de titânio e alumínio (TiAlN) após o torneamento de ferro fundido cinzento sob vc de 300 m.min-1. O principal mecanismo de desgaste encontrado foi o abrasivo, seguido pelo adesivo. Além disso, Liu et al. (2017) verificaram o desgaste adesivo era mais intenso para as ferramentas revestidas devido a duas razões: o atrito entre o revestimento áspero e a peça de trabalho e a maior temperatura de corte resultante da vida mais longa das ferramentas de corte revestidas.

Todavia, Qin et al. (2014) encontraram resultados distintos no torneamento de um ferro fundido (209 HB e $250 \mathrm{MPa}$ ) com insertos de Si3N4 não revestidos e revestidos com nitreto de titânio (TiN) e óxido de alumínio (A12O3). Desgastes abrasivo e adesivo, nessa ordem, ocorreram de forma mais severa sobre as ferramentas sem revestimento. Os autores associaram o desgaste abrasivo a existência de precipitados (carbonetos) no ferro fundido cinzento e a diminuição da dureza das ferramentas de corte em altas temperaturas de corte. Já o desgaste adesivo foi relacionado ao cisalhamento dos pontos de contato entre a ferramenta e a transferência de material entre as superfícies devido alta pressão e temperatura.

Em relação às características microestruturais, Stephenson e Agapiou (2016) e Klocke (2011) explicaram que a estrutura superficial do ferro fundido geralmente exibe menor usinabilidade comparado ao núcleo do material. Isto pode ser atribuído, por um lado, 
a inclusões não metálicas e, por outro lado, à microestrutura da matriz e distribuição e tamanho da grafita alterados diretamente abaixo da camada fundida mais externa, bem como oxidações em altas temperaturas. Tal fato resulta em um desgaste abrasivo mais forte e na formação de um desgaste de entalhe na aresta de corte da ferramenta. No torneamento, isso é frequentemente compensado por meio de uma redução dos parâmetros de corte.

Por fim, conjuntamente à microestrutura, as modificações por alterações de composição química e consequências sobre as propriedades mecânicas convencionais (dureza e limite de resistência à tração) podem auxiliar no entendimento do desgaste de ferramentas durante o corte de ferro fundido cinzento. Nayyar et al. (2013) ao comparar a usinabilidade de dezoito tipos de ferros fundidos vermiculares com dois tipos de ferros fundidos cinzentos observaram que, independentemente do material da peça de trabalho, a vida da ferramenta dependia da microestrutura e das propriedades mecânicas, diminuindo com os aumentos da dureza, da resistência à tração e do teor de perlita. Pereira, Boehs e Guesser (2006) exploraram a influência do teor de enxofre $(0,065-0,18 \%)$ na usinabilidade do ferro fundido cinzento (classe GG25) com ferramentas de metal duro revestidas (carbonitreto de titânio (TICN)+AL2O3+TIN) para vc de 100 m.min-1 e 200 m.min-1. A vida mais longa da ferramenta foi encontrada para os maiores valores de vc e teor de enxofre, devido a formação da camada protetora de MnS. Meurer, Boehs e Guesser (2007) compararam a usinabilidade de um ferro fundido cinzento (FC 250) com outro ferro fundido cinzento adicionado titânio (\%0,0026 em peso) (FC 250-Ti). A adição de titânio não influenciou significativamente no desgaste de flanco da ferramenta cerâmica (ISO CNGA 120412 T com duas camadas de revestimento- A12O3+TiCN), apesar da adição de titânio ter gerado partículas de TiCN na microestrutura do ferro fundido.

Dessa maneira, esse trabalho tem como objetivo caracterizar qualitativamente as superfícies de saída e flanco de ferramentas de corte de metal duro após o torneamento de ferro fundido cinzento adicionado nióbio (0,21-0,24\% em peso) e seu complementar com teor insignificante de nióbio $(0,02 \%$ de nióbio em peso) por meio de análise por microscopia eletrônica de varredura (MEV) e espectrometria de energia dispersiva (EDS). A adição de nióbio é justificada em função das modificações provocadas na microestrutura do ferro fundido cinzento: maior estabilidade da austenita e da perlita (NYLÉN, 2001) e refinamentos da grafita, da perlita e das células eutéticas. Consequentemente, a melhoria de propriedades mecânicas- dureza, resistência à tração, resistência ao desgaste, por exemplo, tem sido favorecida (MOHRBACHER; ZHAI, 2011). Ademais, os ferros fundidos cinzentos são 
muito eficazes para aplicações como polias, carcaças, blocos e cabeçotes de motores, discos e tambores de freio e componentes hidráulicos (GUESSER, 2009). Logo, o desenvolvimento de pesquisas sobre novas ligas de ferros fundidos colabora para manter este material competitivo às necessidades do mercado.

\section{Material and Methods}

O material utilizado neste trabalho foi o ferro fundido cinzento perlítico. Sua classe equivalente seria a EN-GJL-250. Seus principais elementos de liga foram sumarizados na Tabela 1, assim como as faixas de suas principais propriedades mecânicas.

TABELA 1- Principais características e propriedades dos corpos de prova

\begin{tabular}{lcccccccc}
\hline & \multicolumn{4}{c}{ Composição química } & \multicolumn{3}{c}{ Teor de Nb } & \multicolumn{2}{c}{ Propriedades mecânicas } \\
\hline & $\mathrm{C}$ & $\mathrm{Si}$ & $\mathrm{S}$ & $\mathrm{Mn}$ & Baixo & Alto & $\begin{array}{c}\text { Dureza Brinell } \\
(\mathrm{HB})\end{array}$ & $\begin{array}{c}\text { Tensão limite à tração } \\
\left(\sigma_{L R}\right)(\mathrm{MPa})\end{array}$ \\
\hline $\begin{array}{l}\% \mathrm{em} \\
\text { peso }\end{array}$ & $3,42-3,53$ & $1,31-1,41$ & $0,09-0,10$ & $0,43-0,46$ & 0,02 & $0,21-0,24$ & $192-195$ & $291-294$ \\
\hline
\end{tabular}

FONTE: os autores (2020)

Os corpos de provas foram confeccionados com comprimento de $300 \mathrm{~mm}$, diâmetro externo de $80 \mathrm{~mm}$ e interno de $34 \mathrm{~mm}$. A geometria dos corpos de prova garantiu uma espessura de parede de $23 \mathrm{~mm}$ a fim de auxiliar na homogeneidade microestrutural ao longo da seção transversal. Isto, comparado com a condição de um cilindro maciço.

Nos testes foram utilizados insertos de metal duro CNMA e CNMG 120408 classe $\mathrm{K} 20$ revestidos por $\mathrm{Al}_{2} \mathrm{O}_{3}$-TiCN (Mitsubishi UC5115), via deposição química de vapor (chemical vapour deposition). Quanto a geometria do quebra-cavaco, foram encontradas duas possibilidades: Flat Top e GH (Figura 3). Como essas configurações alteraram os ângulos do sistema de referência das ferramentas de corte, o objetivo do uso das distintas geometrias do quebra-cavaco foi observar alterações no mecanismo de formação do cavaco.

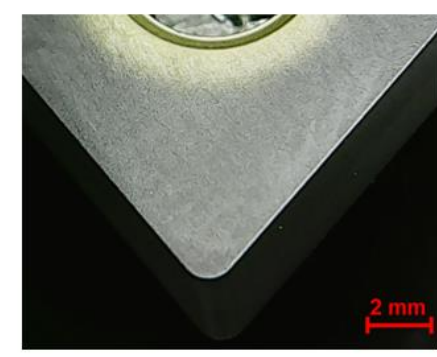

Inserto Sem Quebra-Cavaco (Tipo Flat Top)

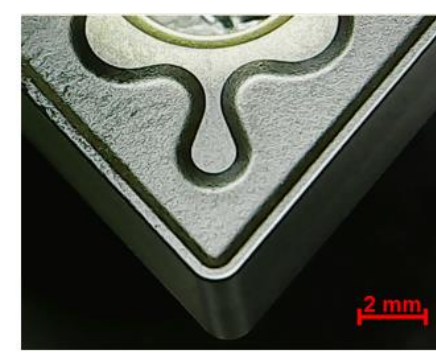

Inserto Com Quebra-Cavaco (Tipo GH)

FIGURA 3 - Fotografias da geometria do quebra-cavaco FONTE: os autores (2021)

Os testes de torneamento foram realizados utilizando um torno Romi Centur $30 \mathrm{~S}$ potência máxima de 5,5 kW e rotação máxima de $3500 \mathrm{rpm}$, com comando 
numérico Mach 9, no Laboratório de Usinagem da UFMG. Os valores de $v_{c}$, fe $a_{p}$ foram estabelecidos considerando os valores empregados na literatura, os limites máximos indicados pelo fabricante, a limitação de rotação máxima do torno e de material da peça. $\mathrm{O}$ valor da $a_{p}$ foi mantido em 1,5 mm. As análises superficiais qualitativas ocorreram após condições de teste na sequência descrita na Tabela 2. Para cada análise superficial foram conduzidos teste e réplica. Totalizaram-se 48 ensaios e 8 análises qualitativas por MEV e EDS.

TABELA 2- Parâmetros de corte e variáveis do processo empregados na análise superficial das ferramentas de corte após o torneamento

\begin{tabular}{|c|c|c|c|c|}
\hline $\begin{array}{l}\text { Material da } \\
\text { Peça }\end{array}$ & $\begin{array}{c}\text { Geometria do } \\
\text { Quebra-Cavaco }\end{array}$ & $v_{c}\left(\mathbf{m} \cdot \mathrm{min}^{-1}\right)$ & $f\left(\mathbf{m m} \cdot \mathbf{r e v}^{-1}\right)$ & $\begin{array}{l}\text { Ordem da análise } \\
\text { superficial (teste e } \\
\text { réplica) }\end{array}$ \\
\hline Baixo $\mathrm{Nb}$ & Flat Top & $240 ; 360 ; 480$ & 0,$25 ; 0,50$ & $1^{\mathrm{a}}$ e $5^{\mathrm{a}}$ \\
\hline Alto $\mathrm{Nb}$ & GH & $240 ; 360 ; 480$ & 0,$25 ; 0,50$ & $2^{a}$ e $6^{a}$ \\
\hline Alto $\mathrm{Nb}$ & Flat Top & $240 ; 360 ; 480$ & 0,$25 ; 0,50$ & $3^{a}$ e $7^{a}$ \\
\hline Baixo $\mathrm{Nb}$ & GH & $240 ; 360 ; 480$ & 0,$25 ; 0,50$ & $4^{a}$ e $8^{a}$ \\
\hline
\end{tabular}

Fonte: os autores (2020)

Para a análise das superfícies de saída e folga das ferramentas, as amostras foram limpas numa solução de álcool etílico em um equipamento de vibração ultrassônica Branson, modelo 1800. Foi utilizado um microscópio JEOL, modelo JSM-IT300, como instrumento para a técnica de microscopia eletrônica de varredura (MEV). Este possuía um equipamento de microanálise acoplado - um detector do EDS Oxford Instruments, modelo $X-M_{a x}{ }^{N}$ - que possibilitou a resolução dos constituintes em área da ordem de micrometro ao quadrado. Para a geração e tratamento dos dados obtidos pelas técnicas de caracterização, utilizou-se o software AZtec e OriginPro 8. Esta etapa foi realizada no Instituto Politécnico da Pontifícia Universidade Católica de Minas Gerais- PUC-MG.

\section{Results and discussion}

As superfícies de saída e de folga das ferramentas de corte obtidas por MEV foram realçadas nas Figuras 4 a 7. De maneira geral, não foi possível afirmar a ocorrência de desgaste nem descrever seus possíveis mecanismos. As análises qualitativas das imagens não revelaram comportamentos distintos das ferramentas de corte em função da geometria do quebra-cavaco. Da mesma forma, a adição de nióbio não foi capaz de influenciar o processo de desgaste das ferramentas de corte. Acredita-se que tais fatos deveram-se à pouca distância usinada (cerca de $810 \mathrm{~mm}$ para cada inserto) associado a fácil usinabilidade do ferro fundido cinzento e aos parâmetros de corte estabelecidos para a realização dos testes. 


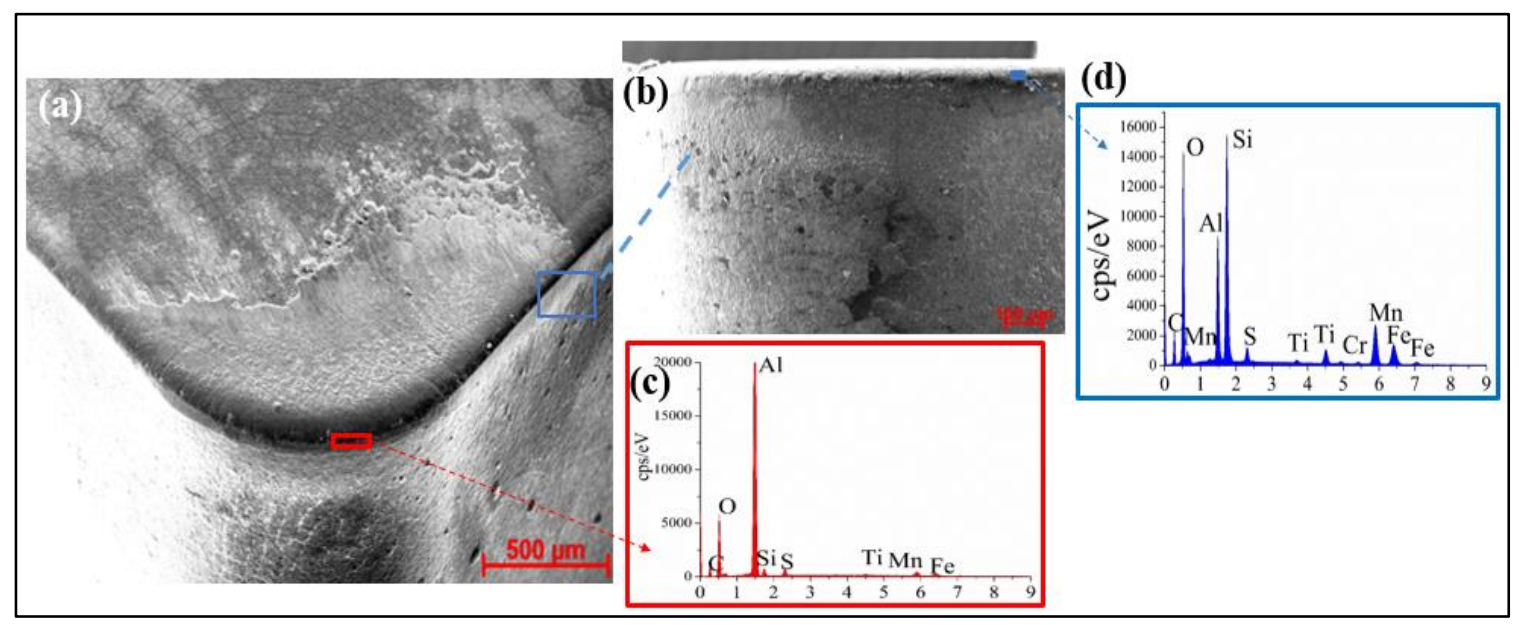

FIGURA 4 - Ferramenta com geometria de quebra-cavaco Flat Top e peças com baixo Nb: (a) MEV da superfície de saída (b) MEV da superfície de folga (c) EDS da aresta de corte (d) EDS do flanco Fonte: os autores (2020)

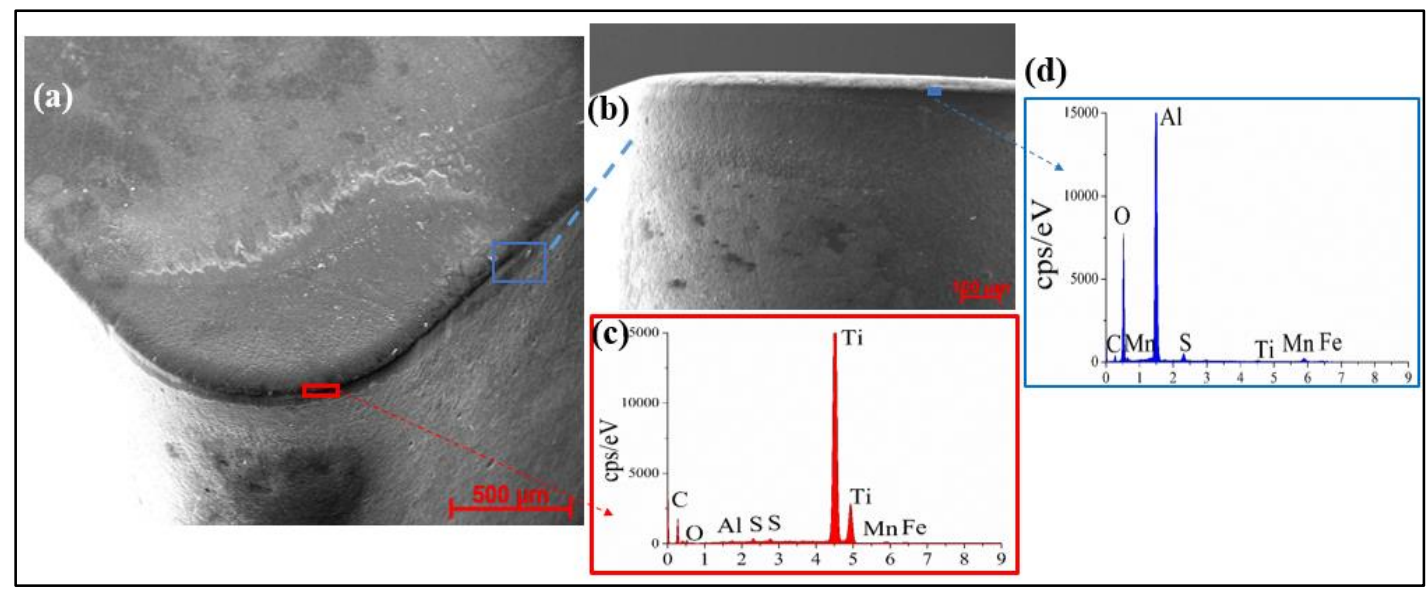

FIGURA 5 - Ferramenta com geometria de quebra-cavaco Flat Top e peças com alto Nb: (a) MEV da superfície de saída (b) MEV da superfície de folga (c) EDS da aresta de corte (d) EDS do flanco Fonte: os autores (2020)

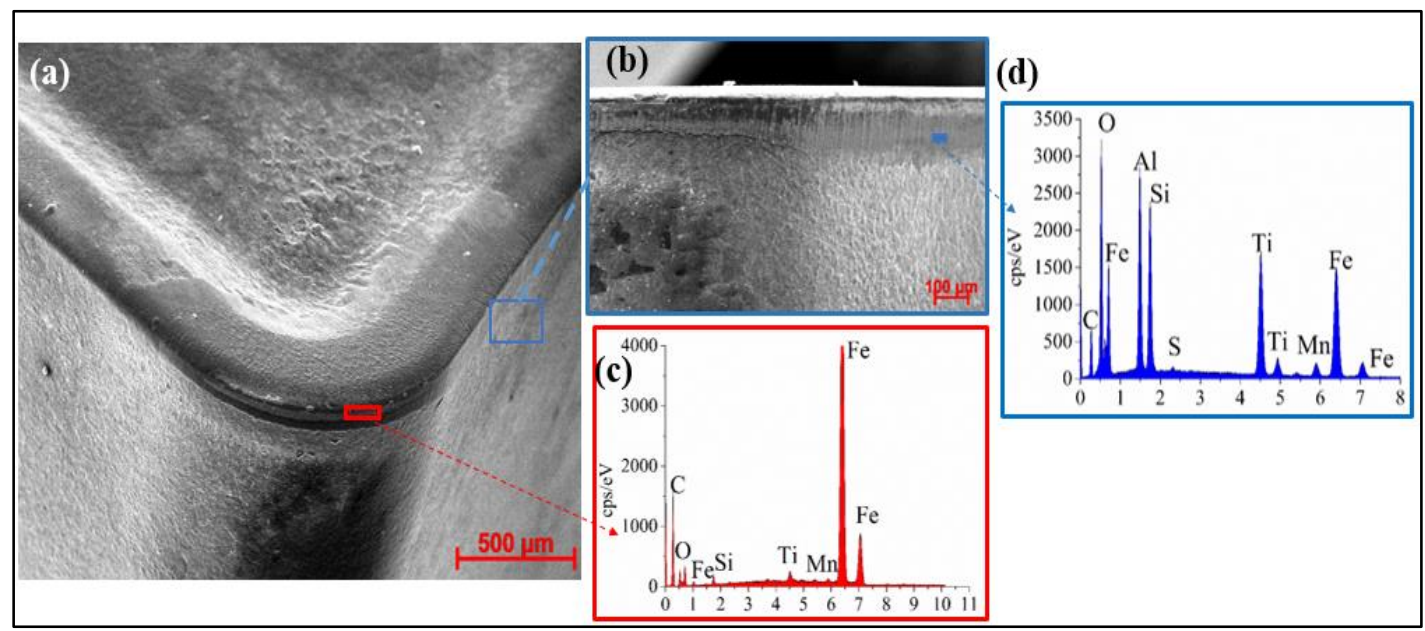

FIGURA 6 - Ferramenta com geometria de quebra-cavaco $G H$ e peças com baixo Nb: (a) MEV da superfície de saída (b) MEV da superfície de folga (c) EDS da aresta de corte (d) EDS do flanco Fonte: os autores (2020) 


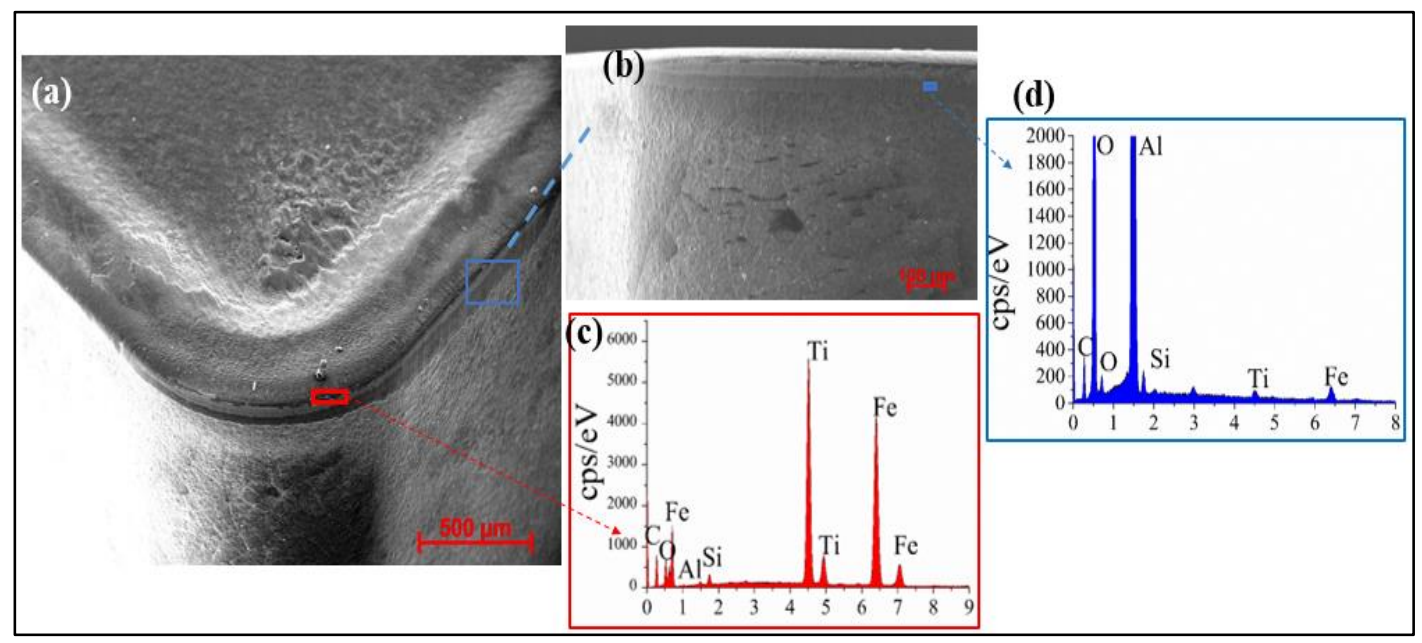

FIGURA 7 - Ferramenta com geometria de quebra-cavaco $G H$ e peças com alto Nb: (a) MEV da superfície de saída (b) MEV da superfície de folga (c) EDS da aresta de corte (d) EDS do flanco

Fonte: os autores (2020)

Para verificar a ocorrência de um processo de retirada do revestimento ou adesão de material do ferro fundido cinzento foi realizada análise EDS em todas as superfícies de saída. Nestas regiões estiveram presentes possíveis zonas de aderência e escorregamento (Figura 4(a), Figura 5(a), Figura 6(a), Figura 7(a)). A ocorrência dos elementos ferro, manganês, silício, enxofre (Figura 4(c), Figura 5(c), Figura 6(c), Figura 7(c)) todos presentes na composição química do ferro fundido cinzento, elucidou a adesão de material dos cavacos. Entretanto, na mesma análise por EDS, foi possível encontrar também elementos do revestimento destas ferramentas (oxigênio, alumínio, titânio e carbono). Tal fato sugeriu que o revestimento não se desgastou. Ademais elementos característicos dos substratos da ferramenta- tungstênio e cobalto, por exemplo, não foram encontrados. Esse resultado também sugere que a espessura dos filmes cerâmicos $\mathrm{TiCN}+\mathrm{Al}_{2} \mathrm{O}_{3}$ supera $5 \mu \mathrm{m}$, máximo alcance dos feixes de elétrons.

Para as regiões de folga (Figura 4(b)(d), Figura 6(b)(d), Figura 7(b)(d), Figura $8(b)(d))$ verificou-se a presença de elementos característicos do ferro fundido cinzento (ferro, manganês, silício e enxofre), caracterizando sua adesão. A presença de manganês e enxofre tanto na superfície de saída quanto no flanco das ferramentas sugere que seria possível um efeito autolubrificante do material devido à presença de inclusões de $\mathrm{MnS}$ nesse material. Heck et al. (2008) comentaram percepções semelhantes. Além disso, percebeu-se a presença de titânio e alumínio para todas as superfícies de folga. Supõem-se que estes elementos pertençam à camada dos revestimentos, logo a adesão ocorreu acima destas camadas. Por fim, foram observadas ranhuras na região desgastada de todos os flancos 
sugerindo o início do mecanismo de abrasão (KLOCKE, 2011), o que seria possível devido à presença de partículas duras, inclusões e carbonetos do ferro fundido estudado.

Por fim, ressalta-se que as regiões onde foram observados os elementos aderidos estão corroborando a afirmação de Ståhl (2012). O autor esclareceu que em consequência do cavaco descontínuo, o comprimento de contato na superfície de saída da aresta de corte às vezes é extremamente curto, favorecendo o surgimento do desgaste da ferramenta na ou nas proximidades da linha da aresta de corte.

Como trabalhos futuros, sugere-se a continuidade dos estudos para amas geometrias de quebra-cavaco sobre maiores velocidades de corte e comprimento de usinagem. Dessa maneira, será possível construir curvas de vida para cada condição de usinagem bem como avaliar a progressão do desgaste da ferramenta para cada geometria de quebra-cavaco.

\section{Conclusion}

Por meio dos resultados dos testes de torneamento do ferro fundido cinzento com diferentes teores de nióbio utilizando-se ferramentas de corte lisas e com quebra-cavaco e diferentes parâmetros de corte, são descritas algumas considerações parciais:

- A adição de nióbio no ferro fundido cinzento e a modificação da geometria de quebra-cavaco da ferramenta de corte foram indiferentes em relação ao desgaste das ferramentas e seus mecanismos.

- Nenhum tipo de avaria significativa (quebra, lascamento ou trinca) ocorreu nas ferramentas de corte analisadas para os parâmetros de corte estabelecidos.

- As análises das imagens por MEV não evidenciaram a ocorrência de desgaste para o comprimento de corte $(810 \mathrm{~mm})$ utilizado em cada ferramenta.

- Verificou-se adesão de material da peça, tanto na superfície de saída quanto na de folga, para todas as ferramentas de corte. Além disso, foram encontradas ranhuras no flanco, sugerindo abrasão.

\section{Acknowledgment}

This work was partly supported by Coordenação de Aperfeiçoamento de Pessoal de Nível Superior - Brasil (CAPES) - Finance Code 001. The authors are grateful to Fundação de Amparo à Pesquisa do Estado de Minas Gerais (FAPEMIG) and Conselho Nacional de Desenvolvimento Científico e Tecnológico(CNPq) for providing financial support, to Companhia Brasileira de Metalurgia e Mineração $\left(\mathrm{CBMM}^{\circledR}\right)$ for the concession of raw materials, and to Serviço Nacional de Aprendizagem Industrial (SENAI) ITAÚNA CETEF for the casting of the material. The authors thank Instituto 
Politécnico da Pontifícia Universidade Católica De Minas Gerais (PUC-MG) for the electronic analysis of the samples.

Este trabalho foi parcialmente financiado pela Coordenação de Aperfeiçoamento de Pessoal de Nível Superior - Brasil (CAPES) - Código Financeiro 001. Os autores agradecem à Fundação de Amparo à Pesquisa do Estado de Minas Gerais (FAPEMIG) e ao Conselho Nacional de Desenvolvimento Científico e Tecnológico (CNPq) pelo apoio financeiro, à Companhia Brasileira de Metalurgia e Mineração (CBMM®) pela concessão de matéria-prima e ao Serviço Nacional de Aprendizagem Industrial (SENAI) ITAÚNA CETEF pela fundição do material. Os autores agradecem ao Instituto Politécnico da Pontifícia Universidade Católica de Minas Gerais (PUC-MG) pela análise eletrônica das amostras.

\section{Bibliography}

COMPANHIA BRASILEIRA DE METALURGIA E MINERAÇÃO. Relatório de análise nº 18619. Araxá: CBMM, 2017.

FIORINI, P.; BYRNE, G. The influence of built-up layer formation on cutting performance of GG25 grey cast iron. CIRP Annals, v. 65, n. 1, p. 93-96, 2016.

GRZESIK, W. Advanced machining processes of metallic materials: theory, modelling and applications. Elsevier, Second Edition, 2017.

GUESSER, W.L. Propriedades mecânicas dos ferros fundidos. Blucher, 2009.

HECK, M.; ORTNER, H. M.; FLEGE, S.; REUTER, U.; ENSINGER, W. Analytical investigations concerning the wear behaviour of cutting tools used for the machining of compacted graphite iron and grey cast iron. International Journal of Refractory Metals and Hard Materials, v. 26, n. 3, p. 197-206, 2008.

KLOCKE, F. Manufacturing Processes 1: Cutting. Springer, 2011.

LIU, W.; CHU, Q.; ZENG, J.; HE, R.; WU, H.; WU, Z.; WU, S. PVD-CrAlN and TiAIN coated Si3N4 ceramic cutting tools-1. Microstructure, turning performance and wear mechanism. Ceramics International, v. 43, n. 12, p. 8999-9004, 2017.

MACHADO, Á. R.; ABRÃO, A. M.; COElHO, R. T. SILVA, M. B. D. Teoria da usinagem dos materiais. Blucher, $2^{\mathrm{a}}$ Edição, 2015.

MEURER, P.R.; BOEHS, L.; GUESSER, W.L. Usinabilidade de ferro fundido cinzento ligado utilizado na fabricação de discos de freios automotivos. In: $\mathbf{4}^{\mathbf{0}}$ Congresso Brasileiro de Engenharia de Fabricação, São Paulo. 2007.

MOHRBACHER, H.; ZHAI, Q. Niobium alloying in gray cast iron for vehicle brake discs. In: AIST Steel Properties and Applications Conference Proceedings-Combined with MS and T'11, Materials Science and Technology. p. 137-148, 2011.

NAYYAR, V.; GRENMYR, G.; KAMINSKI, J.; NYBORG, L. Machinability of compacted graphite iron (CGI) and flake graphite iron (FGI) with coated carbide. International Journal of Machining and Machinability of Materials, v. 13, n. 1, p. 67-90, 2013.

NYLÉN, T. Niobium in cast iron. In: International Symposium on Niobium. 2001. p. 125. 
PEREIRA, A.A. Influência do teor de enxofre na microestrutura, nas propriedades mecânicas e na usinabilidade do ferro fundido cinzento FC 25. 141f. Dissertação (mestrado), Universidade Federal de Santa Catarina, Florianópolis, 2005.

PEREIRA, A.A; BOEHS, L.; GUESSER, W.L. The influence of sulfur on the machinability of gray cast iron FC25. Journal of materials processing technology, v. 179, n. 1-3, p. 165171, 2006.

QIN, J.; LONG, Y.; ZENG, J.; WU, S.Continuous and varied depth-of-cut turning of gray cast iron by using uncoated and TiN/Al2O3 coated silicon nitride-based ceramic tools. Ceramics International, v. 40, n. 8, p. 12245-12251, 2014.

STÅHL, E.J. Metal cutting theories and models. Division of Production and Materials Engineering, 2012.

STEPHENSON, D.A.; AGAPIOU, J.S. Metal cutting theory and practice. CRC press, 2016.

TRENT, E.M.; WRIGHT, P.K. Metal cutting. Butterworth-Heinemann, 2000.

TOOPTONG, S.; PARK, K.H.; KWON, P. A comparative investigation on flank wear when turning three cast irons. Tribology International, v. 120, p. 127-139, 2018.

VELICHKO, A.; HOLZAPFEL, C.; MUECKLICH, F. 3D characterization of graphite morphologies in cast iron. Advanced Engineering Materials, v. 9, n. 1-2, p. 39-45, 2007. 